\title{
A PRIVATIZAÇÃO DA EDUCAÇÃO SECUNDÁRIA NA INGLATERRA POR MEIO DAS SPONSORED ACADEMIES E DAS MULTI-ACADEMY TRUSTS
}

\author{
Maria Vieira Silva ${ }^{1}$
}

\begin{abstract}
RESUMO: Tendo como referência antinomias e paradoxos da democracia no tecido social contemporâneo, este artigo discute algumas mutações do neoliberalismo britânico a partir da gestão da coalizão do Conservative/Liberal Democrat. As análises têm como foco a potencialização das políticas neoliberais na educação pública inglesa, por meio dos programas sponsored academies e multiacademy trusts. A partir de dados coletados em fontes bibliográficas, documentos e legislações, enfocamos a intensificação da lógica mercantil nas reformas da Educação Secundária da Inglaterra e problematizamos a redefinição do sentido público da escola pública no contexto britânico, o qual tem sido referência para muitos estados-nações.
\end{abstract}

Palavras-chave: Reformas educacionais na Inglaterra. Sponsored academies. Multi-academy trusts.

\section{THE PRIVATIZATION OF SECONDARY EDUCATION IN ENGLAND THROUGH SPONSORED ACADEMIES AND MULTI-ACADEMY TRUSTS}

\begin{abstract}
Based on the antinomies and paradoxes of democracy in the contemporary social fabric, this article discusses some mutations of British neoliberalism based on the management of the Conservative/Liberal Democrat coalition. The analysis focus on the empowerment of neoliberal policies in the English public education through the sponsored academies and multi-academy trusts programs. Based on data collected from bibliographic sources, documents and legislation, we focus on the intensification of commercial logic in the reforms of Secondary Education in England and problematize the redefinition of the public meaning of public schools in the British context, which has been a reference for many nation-states.
\end{abstract}

Keywords: Educational reforms in England. Sponsored academies. Multi-academy trusts.

O presente artigo é derivado do projeto de pesquisa Reformas educacionais e trabalho docente no ensino médio sob as influências da nova gestão pública na Inglaterra e no Brasil, com financiamento pelo Conselho Nacional de Desenvolvimento Científico e Tecnológico. 


\title{
LA PRIVATIZACIÓN DE LA EDUCACIÓN SECUNDARIA EN INGLATERRA A TRAVÉS DE LAS SPONSORED ACADEMIES Y DE LAS MULTI-ACADEMY TRUSTS
}

\begin{abstract}
RESUMEN: Teniendo como referencia las antinomias y paradojas de la democracia en el tejido social contemporáneo, este artículo analiza algunas mutaciones del neoliberalismo británico en base a la gestión de la coalición Conservative/ Liberal Democrat. Los análisis se centran en la potencialización de las políticas neoliberales en la educación pública inglesa a través de los programas sponsored academies y multi-academy trusts. A partir de los datos recogidos en fuentes bibliográficas, documentos y legislaciones nos centramos en la intensificación de la lógica mercantil en las reformas de la educación secundaria de Inglaterra, y problematizamos la redefinición del sentido público de la escuela pública en el contexto británico, el cual ha sido referencia para muchos estados y naciones.

Palabras-clave: Reformas educativas en Inglaterra; Sponsored academies. Multiacademy trust.
\end{abstract}

Para os que odeiam a democracia, só existe uma democracia boa, a que reprime a catástrofe da civilização democrática.

Jackes Rancière

A epígrafe acima, extraída da obra de Jackes Rancière, O ódio à democracia, coloca em relevo as vicissitudes e os paradoxos da democracia em uma civilização que, desde seus primórdios, na Grécia Antiga, a enxergava como um insulto. Rancière (2014) incita-nos a desconstruir os habituais sentidos da democracia e repensar os simulacros em torno de seus significados. Destarte, a representação imagética atribuída ao conceito engana por transmitir determinada ideia como real, quando, na verdade, tal ideia não se reverbera no tecido social, uma vez que, de acordo com o filósofo, a essência da democracia é a pressuposição da igualdade, e nossa civilização é essencialmente desigual. Por suposto, o ódio à democracia é sinônimo do ódio à igualdade, dada a legitimação da crença de que o poder da participação é um atributo apenas dos eleitos, ou de um seleto grupo definido por critérios meritocráticos, ou por contínuas heranças de estratos sociais, que ocupam espaços do poder político-econômico. Rancière, ao se reportar às análises do jovem Marx, afirma que ele soube estabelecer um padrão de pensamento a despeito da democracia, mas que ainda não se esgotou:

[...] as leis e as instituições da democracia formal são as aparências por trás das quais e os instrumentos com os quais se exerce o poder da classe burguesa. A luta contra essas aparências tornou-se então a via para uma democracia em que a liberdade e a igualdade não seriam mais representadas nas instituições da lei e do Estado, mas seriam encarnadas nas próprias formas da vida material e da experiência sensível. (Rancière, 2014, p. 9)

Sob tal prisma, faz-se necessário ressaltar o hiato entre a democracia formal e a democracia real, sendo que ambas as dimensões guardam enviesamentos e incompatibilidades. Com efeito, a desigualdade 
estrutural, inerente ao modo de produção capitalista, abala os fundamentos da democracia formal e inviabiliza a materialização da democracia real. Tendo como referência as antinomias e os limites dos processos democráticos presentes no tecido social contemporâneo, as análises que tangenciam esse artigo partem do pressuposto de que a ascendência das dinâmicas privatistas e seus preceitos mercantis se concretizam no campo educacional, em razão da volatilidade dos processos democráticos no âmbito do Estado capitalista.

As conquistas históricas, em prol de uma escola pública, gratuita, estatal e laica, têm sido colapsadas mediante a diluição das fronteiras entre as esferas pública e privada, mesmo em contextos com uma tradição de welfare state forte e políticas sociais consolidadas, como é o caso da Inglaterra. A partir de dados coletados em fontes bibliográficas, documentos e legislações, realizamos análises sobre as diferentes dimensões da instalação da lógica mercantil no âmbito educacional e sua hegemonia nas reformas da educação secundária da Inglaterra. A partir das mutações do neoliberalismo britânico, materializadas na gestão da coalizão do Conservative/Liberal Democrat, desenvolvemos análises sobre a potencialização das políticas neoliberais na educação pública inglesa, por meio dos programas sponsored academies e multi-academy trusts (MAT). As vulnerabilidades do sentido público da escola pública ocorrem de forma contígua às incompatibilidades estruturais entre democracia e capitalismo. Assim, a consolidação e a expansão de programas educacionais de cariz mercantil e antidemocrático no sistema escolar britânico são emblemáticas da ausência da democracia real na sociedade.

\section{Academies na Inglaterra e a Intensificação da Lógica Mercantil na Educação Pública}

Processos privatistas de bens públicos encontram-se expressivamente consolidados na realidade britânica, uma vez que têm ultrapassado fronteiras de agendas governamentais e atravessado distintas configurações políticas, como o Partido Conservador, o Partido Liberal Democrata e o Partido Trabalhista, tendo sua gênese - de forma mais potente - no âmbito das administrações lideradas por Thatcher (1979 a 1990), alcançando a coalizão do Conservative/Liberal Democrat de 2010 a 2015. A coalizão entre o Partido Conservador (sob a liderança de David Cameron) e o partido Liberal Democrata (Nick Clegg) iniciou-se em 12 de maio de 2010, após a renúncia do premiê Gordon Brown, do Partido Trabalhista, e significou um acordo entre os conservadores e os liberais-democratas. Historicamente, na realidade inglesa, o partido com mais parlamentares eleitos do que todos os outros juntos forma um governo, mas, naquele contexto, os conservadores lograram êxito (foram 306 parlamentares eleitos, necessitando 326 para obter a maioria absoluta no Parlamento) e, assim, formaram coalizão com o Partido Liberal Democrata (terceira maior força política do país) e encerraram 13 anos de governo trabalhista.

Segundo Hilton (2019), em sete décadas, foi a primeira vez que a Grã-Bretanha constituiu um governo de coalizão, e a primeira vez que esses dois partidos fecharam um acordo para dividir o poder no governo. $\mathrm{O}$ campo da educação também foi influenciado pela coalizão, uma vez que Michael Gove (Conservative Party) foi Secretário de Estado da Educação e Stephen Twigg (New Labour) foi Secretário de Estado (MP - Member of Parliament Shadow), substituindo Andy Burnham (MP) em 2011. No âmbito da Coalizão Gove, ocorreu a parceria de Sarah Teather (MP, Liberal Democrata) como Ministra de Estado da Infância e da Família. Nick Gibb (MP) foi Ministro de Estado para Padrões Escolares. Ele deixou o governo em uma reforma ministerial em 2012, mas retornou ao mesmo departamento (e ao mesmo cargo) em 2014. Teather renunciou em 2012, e a presença dos Democratas Liberais no Departament for Education teve continuidade por meio de David Laws (MP), nomeado Ministro de Estado para Escolas. Em reconfigurações posteriores, Twigg foi substituído pelo Tristram Hunt (MP) em 2013 e Gove foi substituído por Nicky Morgan (MP) em 2014 (Hilton, 2019). 
A aderência aos princípios e às práticas mercantis na máquina estatal inglesa assume formatos multiformes e apresentam regularidades em contextos distintos, mas os efeitos desse processo gestorial assumem contornos bastante intensos no ensino secundário, no âmbito da coalizão do Conservative/ Liberal Democrat (2010 a 2015), por meio da expressiva expansão das academies, as quais são emblemas da privatização da educação, em nível secundário.

As academies provocaram uma reestruturação do sistema educacional britânico, uma vez que modificaram substancialmente o regime de vinculação das unidades escolares aos entes governamentais no Reino Unido, além de institucionalizarem a participação de setores empresariais e de organizações não governamentais na gestão e no suporte de recursos às escolas públicas.

De acordo com West e Wolf (2018), The Education Act 1944 estabeleceu um sistema nacional de ensino fundamental e médio, compreendendo escolas sob a supervisão geral de local authorities responsáveis pelo financiamento (manutenção) das escolas públicas. A partir de 1988, as escolas passaram a ter autonomia legal e, em vez das local authorities, tornaram-se responsáveis por tomar decisões acerca de vários aspectos, inclusive questões correlatas a finanças e nomeações de profissionais. Ainda segundo os autores, as academies foram gradualmente introduzidas pelo governo trabalhista (Labour Government), com o intuito de substituir as escolas consideradas 'reprovadas' pelo órgão de inspeção escolar, o Office for Standards in Education (OFSTED) ${ }^{1}$. Com efeito, as escolas públicas, ao optarem por se tornar academies, deixam de ser mantidas pelas local authorities e passam a ter vínculos diretos com o governo central. Além dessa mudança, as academies podem ser patrocinadas por empresas, indivíduos, igrejas ou órgãos voluntários, que contribuem para os custos de capital e administração das escolas, sendo os custos da receita cobertos diretamente pelo governo central. Nesse processo, os órgãos patrocinadores - empresas privadas com status de caridade - firmam acordos de financiamento, por meio de contratos, com a Secretaria de Estado. Em 2009, o requisito de contribuições financeiras do patrocinador foi suprimido. No âmbito jurídico-legal, as academies foram institucionalizadas por meio da Learning and Skills Act 2000, a qual alterou algumas seções da Lei de Educação de 1996. Posteriormente, a referida lei foi renomeada como Academies na Lei de Educação de 2002 (legislation.gov.uk, 2002).

Esse programa educacional foi anunciado pela primeira vez em 2000 por David Blunkett, então Secretário de Estado da Educação e Habilidades, em um discurso no qual afirmou que seu objetivo era "melhorar o desempenho dos alunos e interromper o ciclo de baixas expectativas". Com efeito, o discurso governamental induz a conversão de unidades escolares que têm em seu perfil baixo desempenho escolar para a configuração das academies. De acordo com os apologetas desse programa educacional, a The Academies Act 2010 - the Gove Act anunciou uma revolução estrutural abrangente na educação estatal da Inglaterra, tornando-se também a mais bem-sucedida de todas as conquistas da coalizão do Conservative/Liberal Democrat. De acordo com Hilton (2019), tal proposta se tornou democraticamente legítima, politicamente justificável e educacionalmente confiável, em virtude do fato de que tais reformas foram construídas na gestão do New Labor, mas inspiradas pelas reformas educacionais conservadoras anteriores, da era Thatcher. Ainda de acordo com o autor, é explícito o consenso político da coalizão trabalhista/conservadora/liberal em torno das academies e escolas livres, embora existam objeções sutis no âmbito de cada partido.

When Michael Gove became Secretary of State for Education in 2010, few could have realised how far-reaching and transformational his reforms would soon become. The Academies Act 2010 - the Gove Act - not only heralded something of a sweeping structural revolution in state education in England, it became quite possibly the most successful of all the achievements of the Conservative/ Liberal Democrat coalition, made all the more democratically legitimate, politically justifiable and educationally credible by virtue of the fact that Gove's reforms were built upon those of New 
Labour, which were themselves inspired by the preceding Conservative education reforms of the Thatcher era. The Labour/Conservative/Liberal Democrat political consensus surrounding Academies and Free Schools is manifest, though nuanced objections remain from 'wings' within each party. In consideration of the politics surrounding their development, it helps to begin with the recent genealogy. (Hilton, 2019, p. 19)

De acordo com Hilton (2019), as escolas foram incentivadas a se tornarem academies, a fim de ampliar a diversidade no setor estatal e elevar os padrões de qualidade em locais onde a oferta educacional existente fosse inadequada. Esse programa de governo foi acompanhado de outras propostas de intervenção - Education Action Zones (EAZ), Excellence in Cities (EiC) e London Challenge (LC) -, projetadas para melhorar o desempenho escolar. Por meio da legislação Academies Act 2010, o Parlamento do Reino Unido possibilitou a todas as escolas públicas da Inglaterra que se tornassem academies. O referido dispositivo legal apresenta normas e critérios para os convênios com as academies, incluindo arranjos para assistência financeira das academies, diretrizes para acordos entre o Secretário de Estado e as partes conveniadas, processos de implementação de conversão de escolas públicas em academies ou implementação de uma academy, procedimentos para o financiamento por parte das empresas e diretrizes para concessão de terrenos para funcionamento das escolas, dentre outros aspectos (Legislation.gov.uk, 2010).

O processo de conversão de escolas públicas em academies garantiu maior grau de autonomia com relação à definição dos salários dos professores e possibilidade de organização curricular de forma autônoma, ou mesmo discrepante, face ao currículo nacional. No entanto, ainda de acordo com a legislação Academies Act 2010, antes de uma escola pública ser convertida em academy na Inglaterra, a direção da escola deve consultar as pessoas que julgarem apropriadas se a conversão deve ocorrer (Legislation.gov.uk, 2010).

Before a maintained school in England is converted into an Academy, the school's governing body must consult such persons as they think appropriate about whether the conversion should take place. The consultation must be on the question of whether the school should be converted into an Academy. The consultation may take place before or after an Academy order, or an application for an Academy order, has been made in respect of the school. (Legislation.gov.uk, 2010)

Existem diferentes tipos de academies em funcionamento na Inglaterra, mas todas têm o mesmo estatuto jurídico. As academies são escolas públicas, mas possuem financiamento de organizações e empresas não estatais, por meio de um contrato de financiamento juridicamente vinculativo. Essas escolas têm mais autonomia para a organização do currículo e do horário escolar, bem como do controle e da remuneração da equipe de profissionais. Embora existam algumas regularidades no formato de estrutura e funcionamento das academies, há também singularidades definidas a partir de alguns fatores, como os sujeitos responsáveis pela fundação; as justificativas para a criação das academies e os requisitos que os provedores precisam ter na configuração da escola.

De acordo com Hilton (2019), o Partido Conservador introduziu as Escolas Livres, com o propósito de "libertar" todas as escolas do país do controle burocrático e permitir que pudessem moldar seu próprio caráter: "letting our best schools expand isn't enough. We want to see good new schools springing up" (Hilton, 2019, p.3). A Lei das Academies de 2010 permitiu que escolas estatais se convertessem em academies, e grupos de pais, professores, instituições de caridade, universidades e grupos empresariais, comunitários ou religiosos eram considerados legitimados para estabelecer uma escola livre sempre que houvesse "evidência de demanda". Tal diversificação institucional possibilita um mercado educacional, em que a escolha dos pais exerce pressões competitivas sobre as escolas, para melhorar os padrões, dando prosseguimento a uma política da década de 1980, com continuidade nos anos 1990. 
O processo de conversão de escolas em academies na Inglaterra tem sido bastante expressivo na última década. De acordo com Hilton (2019), o sistema educacional inglês tem sido significativamente modificado, mediante um movimento vigoroso no qual milhares de escolas (primárias e secundárias) voluntariamente têm se tornado academies. Tal mutação ocasiona a desvinculação das unidades escolares das local authorities e estabelece conexão direta das escolas com o governo central, incluindo o financiamento: "the landscape of schooling in England has been transformed over the last decade as thousands of schools primary and secondary - have voluntarily become independent of local authorities and funded directly by central government" (Hilton, 2019, p. 39).

Já o processo de implantação das academies ocorreu no final da era do New Labor, de Tony Blair, em 2010, por meio da gestão de seis secretários de Estado (David Blunkett, Estelle Morris, Charles Clarke, Ruth Kelly, Alan Johnson e Ed Balls), perfazendo o quantitativo de 203 sponsored academies no referido período. Contudo, após 2010, essa política educacional continuou em expansão no âmbito da gestão governamental da coalizão conservadora-liberal-democrata. Segundo Hilton (2019), o número e o ritmo da conversão de escolas públicas em academies refletiu a ambivalência que muitos parlamentares trabalhistas (e do movimento trabalhista mais amplo) tinham em relação à essa política educacional. Na seção que se segue, nós nos ateremos especificamente a uma modalidade de academies: as sponsored academies, uma vez que tal modalidade pode ser considerada um dos principais baluartes da política neoliberal na educação.

\section{As Sponsored Academies e a Intensificação do Hibridismo Entre as Esferas Pública e Privada}

No processo de "academização das escolas" na Inglaterra, ressaltamos a expansão da modalidade sponsored academies. De acordo com o relatório do Departament for Education intitulado An Analysis of the Performance of Sponsored Academies, em novembro de 2018, existiam mais de 2.200 academies patrocinadas na Inglaterra, sendo que a mais antiga delas foi inaugurada em setembro de 2002 (United Kingdom, 2019) 2.

A Tabela 1 evidencia o processo de conversão de todas as modalidades de escolas em sponsored academies no período entre 2002 a 2018. Vale destacar o crescimento exponencial entre as escolas públicas estatais (community schools) em sponsored academies. Assim, conforme os dados, entre os anos 2003/2004, apenas quatro escolas estatais foram convertidas em sponsored academies, e, 16 anos depois (2018/2019), esse número passou para 1.165. Dados do Departament for Education concernentes ao desempenho escolar evidenciam que as escolas predecessoras (anteriores ao processo de academização) tinham sido classificadas pelo OFSTED com um desempenho inferior ao conceito "bom" (less than good) ou "inadequado" antes de se converterem em academies. Pelo menos metade das sponsored academies foi classificada como inadequada antes da academização.

Embora dados do relatório do Departament for Education evidenciem o desempenho das escolas como "inferior a bom" ou "não adequado" pelo OFSTED, os autores afirmam que o último resultado da inspeção de uma escola predecessora não reflete necessariamente a classificação que poderia ter recebido se tivesse sido inspecionada imediatamente antes da academização. Em alguns casos, essas inspeções ocorreram alguns anos antes da academização. Portanto, os resultados da inspeção podem subestimar ou superestimar o desempenho da escola imediatamente antes da academização (Tabela 2). O Departament for Education admite ainda que não é apropriado fazer comparações diretas entre o desempenho das sponsored academies e o desempenho das escolas que permaneceram vinculadas às local authorities, uma vez que esses dois grupos de escolas diferem em várias características. 
Tabela 1. Coorte das sponsored academies e o tipo das escolas predecessoras.

\begin{tabular}{|c|c|c|c|c|c|c|c|c|c|c|c|c|}
\hline 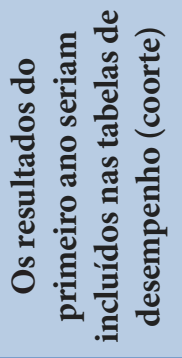 & 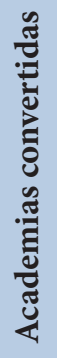 & 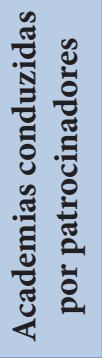 & 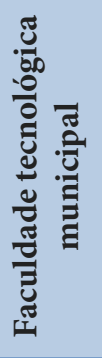 & 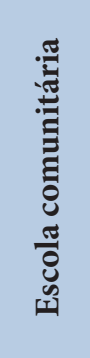 & 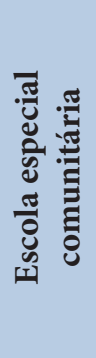 & 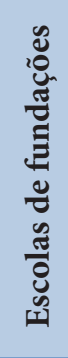 & 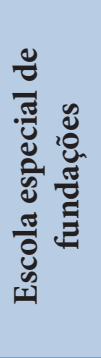 & 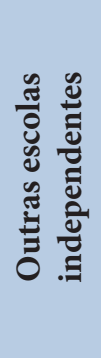 & 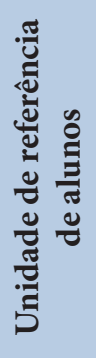 & 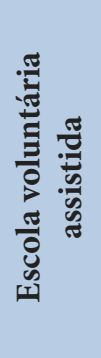 & 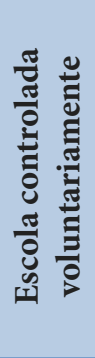 & సี \\
\hline $2002 / 03$ & & & & & & & & & & 1 & & 1 \\
\hline $2003 / 04$ & & & & 4 & & & & & & & & 4 \\
\hline $2004 / 05$ & & & & 2 & & & & & & & & 2 \\
\hline $2005 / 06$ & & & 2 & 2 & & & & & & 2 & & 6 \\
\hline $2006 / 07$ & & & 1 & 12 & & 1 & & & & 1 & & 15 \\
\hline $2007 / 08$ & & & 4 & 13 & & 4 & & 2 & & 2 & & 25 \\
\hline $2008 / 09$ & & & 2 & 21 & & 7 & & 3 & & & 1 & 34 \\
\hline $2009 / 10$ & & & & 32 & & 5 & & 1 & & 2 & & 40 \\
\hline $2010 / 11$ & & & & 32 & & 6 & & 1 & & 5 & & 44 \\
\hline $2011 / 12$ & & & & 23 & & 10 & & & & 3 & & 36 \\
\hline $2012 / 13$ & & 2 & & 112 & 4 & 26 & & & & 6 & 3 & 151 \\
\hline $2013 / 14$ & & & & 245 & 3 & 32 & & 1 & & 20 & 24 & 327 \\
\hline $2014 / 15$ & & 1 & & 215 & 7 & 34 & 1 & & 4 & 32 & 34 & 327 \\
\hline $2015 / 16$ & 1 & & & 142 & 6 & 28 & 2 & & 9 & 39 & 20 & 247 \\
\hline $2016 / 17$ & & & & 91 & 8 & 24 & 1 & & 2 & 14 & 12 & 153 \\
\hline $2017 / 18$ & 1 & & & 149 & 9 & 26 & & & 5 & 32 & 21 & 243 \\
\hline 2018/19 & & & & 70 & 5 & 17 & & & 2 & 20 & 18 & 132 \\
\hline Total & 2 & 3 & 9 & 1.165 & 42 & 220 & 4 & 8 & 22 & 179 & 133 & 1.787 \\
\hline
\end{tabular}

Fonte: traduzido de Hatton, Hampson e Drake (2019).

Tabela 2. Resultados de inspeção do Office for Standards in Education para escolas que precederam as academias patrocinadas

\begin{tabular}{|c|c|c|c|}
\hline $\begin{array}{l}\text { Os resultados do primeiro } \\
\text { ano seriam incluídos nas } \\
\text { tabelas de desempenho }\end{array}$ & $\begin{array}{c}\text { Inferior a bom } \\
(\%)\end{array}$ & Inadequado & Número de escolas \\
\hline $2006 / 07$ & 100 & 25 & 4 \\
\hline $2007 / 08$ & 53 & 27 & 15 \\
\hline $2008 / 09$ & 76 & 7 & 29 \\
\hline $2009 / 10$ & 82 & 10 & 39 \\
\hline 2010/11 & 77 & 12 & 43 \\
\hline $2011 / 12$ & 83 & 11 & 36 \\
\hline $2012 / 13$ & 89 & 25 & 150 \\
\hline $2013 / 14$ & 85 & 39 & 326 \\
\hline $2014 / 15$ & 92 & 61 & 327 \\
\hline $2015 / 16$ & 87 & 54 & 247 \\
\hline $2016 / 17$ & 86 & 50 & 153 \\
\hline $2017 / 18$ & 61 & 16 & 242 \\
\hline $2018 / 19$ & 44 & 9 & 131 \\
\hline
\end{tabular}

Fonte: traduzido de Hatton et al. (2019). 


\section{As Sponsored Academies e o Sistema de Trustes}

No âmbito do capitalismo monopolista, os trustes correspondem à fusão ou à união entre duas empresas de um mesmo ramo ou de áreas diferentes da economia, constituindo uma única companhia ou um grupo de associados de maior porte. A expressão foi adaptada da expressão em inglês "trust", que significa "confiança”.

Na política educacional inglesa, guardadas as especificidades do campo das políticas públicas, os trustes funcionam de forma análoga à do mercado. As sponsored academies contam com patrocinadores individuais ou organizações, como a United Learning Trust, empresas dirigidas por missões, como o The Co-operative Group, ou terceirização com fins lucrativos, por meio de empresas como a Amey PLC. Esse processo de parcerias tinha a expectativa de que os patrocinadores pudessem levar práticas de um gerenciamento inovador para as academies, uma vez que muitas escolas com baixo desempenho poderiam assumir a gestão advinda dessas instituições. Inicialmente, os patrocinadores eram obrigados a contribuir com $10 \%$ dos custos de capital para as academies (até um máximo de 2 milhões de libras). O restante dos custos de capital e de funcionamento era atendido pelo estado da maneira usual para as escolas estatais do Reino Unido, por meio de doações financiadas pela local authority. Mais tarde, o governo removeu a exigência de investimento financeiro por um patrocinador privado, incentivando as escolas a buscarem instituições de caridade para se tornarem patrocinadoras.

No processo de expansão exponencial das academies, foi criado o programa MAT, ou uma cadeia de academies, o qual opera em mais de uma escola. Segundo seus propugnadores, o MAT é uma entidade criada para realizar uma colaboração estratégica visando à melhoria e à manutenção dos altos padrões educacionais em várias escolas. Assim, duas ou mais escolas formam um único MAT, que tem a responsabilidade global pela sua governança e pelo desempenho de cada escola do grupo, embora cada escola possa possuir seu próprio órgão de governo local, que opera sujeito à delegação acordada de poderes do MAT.

Atualmente, existem 1.170 fundos multi-academies na Inglaterra: 29 MATs têm 26 ou mais escolas, 85 têm entre 12 e 25 escolas e 259 têm de 6 a 11 escolas. A maioria dos MATs (598) tem cinco ou menos escolas. Um contrato principal de financiamento com o MAT e acordos de financiamento suplementares com cada escola individual são assinado pelo Secretário de Estado da Educação. As academies que fizerem parte de um MAT têm todos os funcionários sob a responsabilidade do diretor executivo (o CEO, chief executive officer) (OpenLearn, 2018)

De acordo com seus propugnadores, o MAT é uma proposta bastante exitosa. Isso porque as escolas compartilham uma provisão e experiências entre si, sendo uma aspiração governamental de pelo menos duas décadas atrás. Eles afirmam ainda que propostas análogas já operaram em contextos anteriores. Destarte, no início dos anos 2000, existia a proposta de redes e federações escolares, que permitiam que escolas que apresentassem baixo desempenho acadêmico pudessem aprender com as escolas consideradas bem-sucedidas, ensejando uma rede mais flexível ao nível da parceria formalmente constituída. Essa proposta é chamada de trust, porque opera predominantemente como instituições de caridade (sem fins lucrativos), as quais organizam grupos de escolas em termos de criação de políticas comuns, racionalização, organização escolar, compartilhamento de conhecimentos - incluindo empréstimos de recursos humanos e equipamentos (OpenLearn, 2018).

De acordo com o grupo de empresas independentes de consultoria e contabilidade Hacker Young Associates ${ }^{3}$, o Trust Multi-Academy funciona com a seguinte dinâmica: 
- Suporte: a estrutura formal permite mais apoio de escola para escola, de modo que escolas menores podem se beneficiar da experiência e das habilidades presentes em escolas mais fortes ou maiores. Queremos encorajar, apoiar e desafiar os melhores líderes a assumir a responsabilidade por mais escolas e trazer sua experiência em melhoria escolar para beneficiar mais crianças" (Department for Education, 2016, p. 6)

- Economias de escala: MATs incentivam economias de escala em serviços compartilhados, como finanças e administração, ou seja, academies do MAT podem frequentemente negociar contratos e serviços, melhorando o custo-benefício (idem, p.6).

No entanto, essa proposta também tem sido alvo de críticas, as quais contribuem para diminuir ou mesmo suprimir o apoio por parte das local authorities. Os trust são geridos nas business lines e recebem financiamento do governo central, mas tomam todas as decisões sobre como o dinheiro é gasto, tendo autonomia para equilibrar as contas. O CEO, uma função importada do mundo dos negócios, tem foco em orçamentos, défices, prestação de serviços e redução de custos, assumindo pouca ênfase no ensino e na aprendizagem, exceto quando estiver próximo dos exames de avaliação externa (OpenLearn, 2018).

Embora as sponsored academies e os MATS tenham se consolidado como políticas educacionais hegemônicas no âmbito da coalizão do Conservative/Liberal Democrat, manifestações contrárias também tornaram-se candentes no contexto inglês. Na seção que se segue, apresentaremos algumas expressões de resistência a essas políticas educacionais, por parte dos movimentos de docentes e sindicatos.

\section{As Sponsored Academies a Partir de uma Perspectiva Crítica: as Vicissitudes da Proposta}

Embora as academies patrocinadas pretendessem resolver o problema das escolas com baixo desempenho acadêmico ou nas escolas situadas em comunidades com crianças e jovens considerados com baixas aspirações acadêmicas, a House of Commons Education and Skills informou, poucos anos após a implantação do programa, em março de 2005, que seria prudente limitar o programa a 30 ou 50 academies, para avaliar os resultados antes de expandi-lo, uma vez que a rápida expansão da política de academies vem às custas de uma avaliação muito austera para as escolas. O referido comitê estava preocupado com o fato de os resultados promissores alcançados por algumas academies serem devido ao aumento da exclusão de alunos mais difíceis de ensinar. O referido órgão constatou que duas academies de Middlesbrough expulsaram 61 alunos, em comparação com apenas 15 das outras escolas secundárias (K12 Academics, 2019).

O programa de criação de academies também foi criticado por delegar responsabilidades pela gestão a empresários do setor privado, os quais, em muitos casos, não têm experiência no setor educacional, como é o caso do empresário do setor de automóveis, cristão evangélico, Sir. Peter Vardy, acusado de promover o ensino do criacionismo ao lado da macroevolução em academies da Emmanuel Schools Foundation. Tal aspecto também evidencia a presença de grupos religiosos na educação pública por meio de programas promovidos pelo governo do New Labour, uma vez que muitas academies - uma estimativa indica "mais da metade" - são patrocinadas por grupos religiosos ou organizações/indivíduos com uma afiliação religiosa (K12 Academics, 2019).

Contrapondo-se a perspectiva governamental, Steve Sinnott, do National Teachers Union, afirmou que as academies tentam impedir a entrada de crianças que não obtiveram bons resultados ou tiveram dificuldades de aprendizado. Uma resolução para a conferência anual do sindicato solicitou uma campanha 
contra os planos do governo de ter 200 das escolas estatais independentes na Inglaterra (BBC News, 2014). Além disso, um relatório parlamentar de 2015, intitulado Academies and free schools: Government Response to the Committee's Fourth Report of Session 2014-15, recomenda que "pare de exagerar o sucesso das academias e seja cauteloso com conclusões definitivas, exceto onde as evidências o merecerem. A academização nem sempre é bem-sucedida nem é a única alternativa comprovada para uma escola em dificuldades" (House of Commons Education Committee, 2015, p. 12).

Em dezembro de 2012, o Comitê de Contas Públicas da Câmara dos Comuns questionou Henry Stewart, da Rede de Escolas Locais, e Rachel Wolf, da Rede de Novas Escolas, sobre a prestação de contas e o financiamento de academies e escolas gratuitas. O comitê analisou um relatório do auditor geral, gerenciando a expansão do programa de academias, o qual identificou que, entre 2011 e 2012, 96.000.000 libras foram desviadas do apoio às escolas vinculadas a local authorities com desempenho insatisfatório e mais 400.000.000 libras no exercício de 2012 a 2013 para o programa de academias. O comitê também questionou Chris Wormald, então Secretário Permanente do Departament for Education, que admitiu que o governo escolhera deliberadamente remover o dinheiro alocado originalmente para apoiar escolas com desempenho insuficiente. Chris Wormald declarou: "o governo tomou uma decisão muito consciente de que seu principal programa de aprimoramento escolar era o programa de academie" (Idem).

Em 2016, um estudo do Instituto de Políticas Educacionais não encontrou diferenças significativas no desempenho entre as academies e as escolas administradas pelo conselho local, e a confiança de várias academies que administra pelo menos cinco escolas teve um desempenho pior do que as escolas administradas pelo conselho local. O programa original da City Academy apresentou problemas com seu financiamento: custou, em média, 25 milhões de libras para construir uma unidade de academy, e grande parte da qual foi absorvida pelos custos de novos edifícios. Os críticos afirmam que isso é significativamente maior do que o valor para construir uma nova escola da local authority (K12 Academics, 2019)

As academies também apresentam problemas na remuneração da equipe de profissionais, sendo isentos de todos os contratos de remuneração e condições de trabalho. De acordo com dados da pesquisa nacional do governo sobre gênero e remuneração em 2018, as mulheres que trabalham nas redes de academies sofrem algumas das piores disparidades salariais entre homens e mulheres no Reino Unido. Das 50 organizações com as maiores disparidades salariais de gênero publicadas na referida pesquisa, quase a metade é vinculadas a várias academies. As mulheres enfrentam défices médios de remuneração horária de mais de 50\%. (The Guardian, s.d.b)

No âmbito dessa problemática, destaca-se o Schoolsworks Academy Trust, uma cadeia de seis escolas em West Sussex, onde a diferença da média salarial a favor dos homens é de 62\%, o que significa que uma mulher recebe 38 centavos por cada 1 libra ganha por um homem. O Wakefield City Academies Trust, que entrou em colapso no final de 2017, ao administrar 21 escolas, mostrou uma diferença salarial entre os sexos de 52\%, também de acordo com o salário médio por hora. Os trabalhistas propuseram legislação para sujeitar as academies às mesmas regras de responsabilidade das local authorities, mas foram rejeitados pelos conservadores (Idem). A desigualdade de gênero é reconhecida por Jo Swinson, vice-líder dos Democratas Liberais e ex-ministra da igualdade, ao afirmar que: "mulheres profissionais e bem qualificadas são a força motriz em nossas escolas e faculdades, mas ainda vemos níveis chocantes de desigualdade de gênero, com os níveis mais altos de algumas relações de confiança predominantemente dominadas pelos homens" (Idem).

O processo de academização de escolas estatais apresenta problemas também no que se refere ao desempenho dos alunos. Contrariando o argumento de que a conversão das escolas estatais em 
academies promoveria a eficácia no processo de escolarização e a melhoria do desempenho das escolas consideradas reprovadas pelo OFSTED, o próprio Departament for Education reconhece assimetrias no aprendizado de alunos de estratos desfavorecidos. Em 2017, os alunos desfavorecidos em 12 das 58 cadeias alcançaram da média nacional acima daquela de alunos desfavorecidos em todas as escolas regulares, incluindo três cadeias que estavam substancialmente acima dessa média. No entanto, 38 dos 58 ficaram abaixo da média convencional, incluindo oito que estavam bem abaixo da média.

Ainda de acordo com o relatório An analysis of the performance of sponsored academies: Analytical research report, de 2019, os trusts que tiveram mais sucesso com os alunos desfavorecidos também tenderam a ter sucesso com os alunos mais abastados, enquanto aqueles que tiveram menos sucesso tenderam a ter resultados ruins para os dois grupos. A análise de 5 anos mostra que, em comparação com o padrão nacional, o desempenho geral de alunos desfavorecidos em academias patrocinadas piorou levemente de 2013 a 2016, embora em 2018 tenha mostrado sinais de recuperação. O relatório atribui a dificuldade de um desempenho ascendente em razão da mudança para um currículo mais acadêmico ocasionado pelas academias patrocinadas. As 26 cadeias de escolas (trusts) que fizeram parte da pesquisa tinham porcentagem menor de escolas abaixo do padrão do que no âmbito nacional.

\section{Considerações Finais}

Estudos voltados à realidade inglesa permitem constatar idiossincrasias derivadas de um processo de verticalização de ações privatistas na máquina estatal, implementadas sobretudo durante a gestão da Primeira-Ministra Margareth Thacher e corporificadas nas gestões sucedâneas, sejam no âmbito de governos do Partido Conservador, do Partido New Labour ou da coalizão Conservative/ Liberal Democrat. Embora a Inglaterra tenha sido um emblema de políticas governamentais baseadas em diretrizes políticas e econômicas do welfare state e do keynesianismo em diferentes contextos, paradoxalmente, tem sido também uma referência de paradigmas governamentais referenciados na doutrina neoliberal.

Essa doutrina tem ensejado uma reengenharia estatal com diretrizes políticas que primam pelo encolhimento do estado e pela adoção de mecanismos do setor privado. Sua lógica adentrou de forma potente e sem precedentes nas reformas educacionais da Inglaterra, promovendo mudanças substanciais na estrutura e no funcionamento das escolas públicas inglesas, a partir do início dos anos 2000.

De acordo com Lord Adonis, do Partido Trabalhista e um dos formuladores desta política educacional, as academies são a melhor maneira de «violar o muro de Berlim educacional entre a educação privada e estatal» Essa máxima evidencia uma perspectiva política em sintonia com os axiomas da privatização. O campo semântico que sustenta a máxima constitui um discurso ideológico, que visa legitimar transformações profundas nas administrações públicas, e, em específico, na educação pública, e evidencia a prevalência de uma dimensão político-ideológica na gestão da educação pública, em detrimento de uma efetiva eficiência das sponsored academies por um conjunto de fenômenos díspares:

- As academies potencializam certo darwinismo social, uma vez que selecionam alunos ou mesmo expulsam aqueles que possuem um desempenho inferior, visando obter melhores resultados nos exames. 
- As academies são escolas estatais convertidas, possuem status de escolas independentes e podem operar fora das regulações institucionais do School Teachers' Pay and Conditions Document (STPCD).

- Tem sido crescente o movimento de pais e professores contrários à conversão de escolas estatais em academies ${ }^{4}$.

- Algumas academies têm apresentado baixo desempenho, contrapondo-se ao discurso de que a academização visa à melhoria do processo de aprendizado 5 .

- Há deslocamento de verbas governamentais de escolas estatais mantidas pelas local authorities com desempenho insatisfatório para as academies. As escolas estatais vinculadas às local authorities enfrentaram um corte de financiamento de 413 milhões de libras entre 2011 e 2013 (148 milhões de libras em 2011/2012 e outros 265 milhões de libras em 2012/2013).

- As academies potencializam os processos de privatização da educação.

- Há em curso um expressivo processo de resistência às academies ensejado pelos sindicatos ${ }^{6}$. As entidades sindicais são implacavelmente opostas ao funcionamento das academies e afiliadas à Anti-Academies Alliance, a qual realiza uma campanha vigorosa para manter as escolas vinculadas às local authorities e impedir a abertura de academies adicionais.

Os elementos listados apresentam algumas das controvérsias e inconsistências presentes nos programas de privatização da educação na realidade britânica, no entanto, sob a ótica dos partidos trabalhista e conservador, tais programas proporcionaram êxito ao sistema educacional nos últimos 25 anos. Embora o discurso oficial busque veicular a ideia de que a estrutura e o funcionamento das academies garantam maior êxito educacional, essa proposta está eivada de críticas advindas de professores, sindicatos, pais e pesquisadores, tanto pelos altos custos para sua implantação quanto pelo processo de privatização da educação secundária que elas ensejam. Com efeito, a privatização no campo educacional concerne à diferentes estratégias de instalação da lógica mercadológica no âmbito das instâncias públicas ou à gestão da esfera pública por entidades não estatais, tal como podemos depreender da caracterização dos diferentes formatos de academies na Inglaterra, mediante um hibridismo entre o setor público e privado.

As consequências de tal hibridismo é um deslocamento do âmbito de referência público para a esfera econômica e os modelos gerenciais do mercado, em detrimento dos aspectos políticos e sociais. No caso dos processos de privatização sedimentados pelas academies, na realidade inglesa, é possível apreender mecanismos que se processam por meio do fornecimento público com financiamento privado, como é o caso das sponsored academies. Nessa modalidade de parcerias, as entidades patrocinadoras têm prerrogativas para influenciar no processo de funcionamento das escolas, incluindo a organização do currículo.

Os formatos assumidos pelas academies na Inglaterra assumem uma nova estratégia de privatização do ensino público, que se efetiva por uma relação simbiótica entre o público e o privado.

Os dados evidenciaram também que alguns princípios da "revolução neoconservadora" da gestão de Thatcher tornaram-se perenes (guardadas as devidas proporções, em função de variáveis conjunturais), uma vez que se constituíram em políticas de Estado, materializadas pelas políticas de governos, mesmo com composições político-partidárias distintas. No campo educacional, as administrações públicas veiculam o discurso da eficiência dos processos organizacionais empresariais. No entanto, problemas objetivos, correlatos ao funcionamento de escolas vinculadas ao programa sponsored academies e trusts, evidenciam inconsistências graves em suas dinâmicas organizacionais, os quais contradizem o discurso 
da eficiência e da eficácia da gestão mercantil. Superado esse argumento, é possível afirmar que esse programa intenta intensificar mecanismos para veiculação de um ethos empresarial no interior da escola pública, visando à formação de capital humano, de acordo com os desígnios mercantis. Tais programas são emblemas do neoliberalismo em ação e expressões do movimento dialético da relação entre Estado e forças econômicas em presença. Assim, a desconstrução do mito da eficácia mercantil na gestão das escolas estatais é crucial para alimentar a luta pela garantia da escola, de fato pública, e seus princípios democráticos. É premente provocar rupturas com a racionalidade mercantil, que pretende suplantar os princípios da educação pública, como direito social e conquista democrática, parcialmente obtida após anos de lutas, sob o slogan da igualdade de oportunidades, historicamente vinculada com o processo social de construção da cidadania.

\section{Notas}

1. Esse setor é um departamento não ministerial do governo do Reino Unido, subordinado ao Parlamento. O OFSTED é responsável por inspecionar uma série de instituições educacionais, incluindo escolas estaduais e algumas independentes. Ele também inspeciona os serviços de assistência à infância, adoção e promoção, além do treinamento inicial de professores, e regula os primeiros anos de escolarização e os serviços de assistência social infantil.

2. Em $2017,73 \%$ das academies eram administradas pela multi-academy trusts. Isso significa que as academies agrupadas em um multi-academy trust podem compartilhar um mesmo conselho de administração, um mesmo diretor ou equipes de administração ou até mesmo materiais didáticos, produtos de limpeza etc.

3. Empresa do Reino Unido, a qual é o órgão organizador do UHY Hacker Young Group, um grupo de empresas independentes de consultoria e contabilidade. Cada uma das firmas-membro é autônoma e independente. Uma lista delas está disponível no site https://www.uhy-uk.com/

4. “Os pais estão cada vez mais liderando as batalhas contra as escolas que são convertidas em academies, que são escolas estaduais independentes dos conselhos locais, à medida que se tornam mais conscientes das histórias negativas. $\mathrm{O}$ aumento do uso de WhatsApp e grupos de mídia social que conectam pais opostos em todo o país, incluindo aqueles que tiveram sucesso em sua luta, também incentivou as famílias. A promessa do trabalho de acabar com a conversão forçada de escolas locais em academies em sua conferência anual, onde condenaram os salários 'gordos' dos CEOs das cadeias de academies, acrescentou combustível ao incêndio" (Busby, 2019, tradução livre).

5. “Elogiado por Ofsted alguns meses antes de ingressar no Wakefield City Academies Trust, Kinsley viu os padrões despencarem bem abaixo da média nacional. 'Eu tive que ir aos professores para pedir trabalhos de casa. Eu tive que discutir com eles para mudar os livros de leitura do meu filho. Eu ensinei a ele todas as suas tabuadas em casa”, diz Sarah Jones, que tem dois filhos na escola”. (The Guardian, s.d.c, tradução livre).

6. NASUWT, sindicato que representa professores e diretores, vinculado a Trades Union Congress (TUC ); UNISON The Public Service Union, Unite, foi formada em 1993 pela fusão de três sindicatos do setor público: NALGO, NUPE e COHSE.

\section{Referências}

BBC NEWS. Teachers 'oppose city academies'. [s.1.]: BBC New; 2014. Disponível em http://news.bbc.co.uk/2/ hi/uk_news/education/4348931.stm. Acesso em: 27 out. 2020.

HARCKER YOUNG (UHY). Multi-Academy Trusts. United Kingdom: [s.n.]; 2018. Disponível em https:// www.uhy-uk.com/wp-content/uploads/Multi-academy-trusts-explained-our-review-and-insights.pdf. Acesso em: 27 out. 2020 .

HILTON, A. Academies and Free Schools in England: A History and Philosophy of the Gove Act. New York: Galiard, 2019. 
HOUSE OF COMMONS EDUCATION COMMITTEE. Academies and free schools: Government Response to the Committee's Fourth Report of Session 2014-15. United Kingdom: House of Commons Education Committee, 2015.

K12 ACADEMICS. Criticism of and Opposition to the Academies Scheme. [s.l.]: [s.n.]; 2019. Disponível em https://www.k12academics.com/Education\%20Worldwide/Education\%20in\%20the\%20United\%20 Kingdom/Education\%20in\%20England/Academy. Acesso em: 27 out. 2020.

LEGISLATION.GOV.UK. Education Act 2002. United Kingdon: [s.n.], 2002. Disponível em http://www. legislation.gov.uk/ukpga/2002/32/contents. Acesso em: 27 out. 2020.

LEGISLATION.GOV.UK. Academies Act 2010. United Kingdon: [s.n.], 2010. Disponível em http://www. legislation.gov.uk/ukpga/2010/32/section/1. Acesso em: 27 out. 2020.

NACIONAL EDUCATION UNION. Privatisation update Jan 2020 Issue 84 Academies, free schools and privatisation News. Disponível em https://neu.org.uk/media/8401/view. Acesso em 15-04-2020

NATIONAL EDUCATION UNION. Pay scales in academies and trusts. [s.l.]: [s.e], 2019.

OPENLEARN. So What is a 'Multi-Academy Trust'? [s.l.]: [s.n.], 2018. Disponível em https://www.open. edu/openlearn/education-development/education/so-what-multi-academy-trust\#. Acesso em: 27 out. 2020.

POLITICS.CO.UK. Academies. What Are Academies? [s.l.]: [s.n.], [s.d.]. Disponível em https://www. politics.co.uk/reference/academies. Acesso em: 27 out. 2020.

RANCIĖRE, J. O ódio à democracia. São Paulo: Boitempo Editorial, 2014.

THE GUARDIAN. Gender pay gaps in academy school chains among the worst in UK. The Guardian, [s.d.b]. Disponível em https://www.theguardian.com/news/2018/mar/25/gender-pay-gaps-in-academy-schoolchains-among-the-worst-in-uk. Acesso em: 27 out. 2020.

THE GUARDIAN. The great academy schools scandal. The Guardian, [s.d.c]. Disponível em https://www. theguardian.com/education/2018/jul/22/academy-schools-scandal-failing-trusts. Acesso em: 27 out. 2020.

UNITED KINGDOM. Department for Education. An Analysis of the Performance of Sponsored Academies: Analytical Research Report. United Kingdon: Department of Education, 2019. Disponível em https://assets. publishing.service.gov.uk/government/uploads/system/uploads/attachment_data/file/772088/Sponsored_ Academy_Research_Report.pdf. Acesso em: 27 out. 2020.

WEST, A.; WOLF, D. Academies, the School System in England and a Vision for the Future. Matrix Chambers, 2018. Disponível em https://core.ac.uk/download/pdf/158368368.pdf. Acesso em: 27 out. 2020.

HALL, D.; GUNTER, H. A nova gestão pública na Inglaterra: a permanente instabilidade da reforma neoliberal. Educação \& Sociedade, Campinas, v. 36, n. 132, p. 743-758, jul./set. 2015.

K12 ACADEMICS. Criticism of and Opposition to the Academies Scheme. [s.l.]: [s.n.]; 2019. Disponível em https://www.k12academics.com/Education\%20Worldwide/Education\%20in\%20the\%20United\%20 Kingdom/Education\%20in\%20England/Academy. Acesso em: 27 out. 2020.

LAVAL, C. A escola não é uma empresa. São Paulo: Boitempo, 2019. 
NACIONAL EDUCATION UNION. Privatisation update Jan 2020 Issue 84 Academies, free schools and privatisation News. Disponível em https://neu.org.uk/media/8401/view. Acesso em 15-04-2020

TAYLOR-GOOBYT, P. Welfare, hierarquia e a "nova direita" na era Thatcher. Lua Nova. No 24. São Paulo, Set. 1991. Disponível em http://www.scielo.br/scielo.php?script=sci_arttext\&pid=S010264451991000200009\#nt00. Acesso em: 21/11/2019

\section{Sobre a Autora}

Maria Vieira Silva é Doutora em Educação pela Universidade Estadual de Campinas, com estágio pósdoutoral no Centre de Recherches Sociologiques e Politiques de Paris da Université Paris VIII e na Universidade Federal de Minas Gerais. Professora titular da Faculdade de Educação da Universidade Federal de Uberlândia e coordenadora do Grupo de Pesquisa Polis, Políticas, Educação e Cidadania.

Recebido: 31 jul. 2020

Aceito: 12 out. 2020 